\title{
Erratum to: Body mass index and random blood glucose levels in a semi urban Nigerian community
}

\author{
E. E. J. Iweala • S. N. Chinedu • I. S. Afolabi • \\ O. O. Ogunlana • D. E. Azuh • V. C. Osamor • \\ T. A. Toogun
}

Published online: 8 May 2014

(C) Research Society for Study of Diabetes in India 2014

\section{Erratum to: Int J Diabetes Dev Ctries}

DOI 10.1007/s13410-013-0177-4

In the original publication of this article (10.1007/s1341017013-0177-4) the family name of the sixth author should read as "Osamor".

The online version of the original article can be found at http://dx.doi.org/ 10.1007/s13410-013-0177-4.

E. E. J. Iweala $(\varangle) \cdot$ S. N. Chinedu $\cdot$ I. S. Afolabi $\cdot$ O. O. Ogunlana Department of Biological Sciences, Covenant University, Ota, Ogun State, Nigeria

e-mail: emekaiweala@hotmail.com

D. E. Azuh

Department of Economics and Development Studies, Covenant

University, Ota, Ogun State, Nigeria

\section{C. Osamor}

Department of Computer and Information Sciences, Covenant

University, Ota, Ogun State, Nigeria

\section{T. A. Toogun}

Covenant University Health Center, Covenant University, Ota, Ogun

State, Nigeria

E. E. J. Iweala $\cdot$ S. N. Chinedu $\cdot$ I. S. Afolabi $\cdot$ O. O. Ogunlana

D. E. Azuh • V. C. Osamor · T. A. Toogun

Covenant University Public Health and Wellbeing Research Group

(CUPHWERG), Covenant University, Ota, Ogun State, Nigeria 